\title{
Synthesis and Characterization of Nanocrystalline $\mathrm{Ni}_{50} \mathbf{A l}_{50-x} \mathbf{M o}_{x}(x=0-5)$ Intermetallic Compound during Mechanical Alloying Process
}

\author{
A. Khajesarvi and G. H. Akbari \\ Department of Materials Science and Engineering, Shahid Bahonar University, Kerman 76135-133, Iran \\ Correspondence should be addressed to A. Khajesarvi; alikhajesarvi@yahoo.com
}

Received 13 March 2015; Accepted 9 August 2015

Academic Editor: Ipsita Banerjee

Copyright @ 2015 A. Khajesarvi and G. H. Akbari. This is an open access article distributed under the Creative Commons Attribution License, which permits unrestricted use, distribution, and reproduction in any medium, provided the original work is properly cited.

\begin{abstract}
Nanocrystalline $\mathrm{Ni}_{50} \mathrm{Al}_{50-x} \mathrm{Mo}_{x}(x=0,0.5,1,2.5,5)$ intermetallic compound was produced through mechanical alloying of nickel, aluminum, and molybdenum powders. Powders produced from milling were analyzed using scanning electron microscopy (SEM) and X-ray diffractometry (XRD). Results showed that, with increasing the atomic percent of molybdenum, average grain size decreased from 3 to $0.5 \mu \mathrm{m}$. Parameter lattice and lattice strain increased with increasing the atomic percent of molybdenum, while the crystal structure became finer up to $10 \mathrm{~nm}$. Also, maximum microhardness was obtained for $\mathrm{NiAl}_{49} \mathrm{Mo}_{1}$ alloy.
\end{abstract}

\section{Introduction}

There is an increasing interest in producing nanocrystals because of their excellent physical and mechanical properties in comparison to coarse-grain materials [1]. NiAl intermetallic compound can be used as a high-temperature material owing to its high melting point, low density, excellent thermal conduct, good temperature stability, and good oxidation resistance [2-5]. Unfortunately, this compound has a big disadvantage: low toughness at low temperature and low creep strength at high temperatures, which limits the application of this intermetallic compound [6]. Considerable efforts have been made in terms of increasing the mechanical properties of NiAl via reducing the size of materials microstructure to nanometer dimension, micro- and macroalloying, and using alloying elements [7-9]. Although extensive research has been done on this alloy, recent investigations on revealing interesting properties of $\mathrm{NiAl}$ system are still continuing so that promising results have been obtained in terms of improving fragility through modifying grain size [10-14].

Several methods like powder metallurgy, self-combustion synthesis, and mechanical alloying have been used for synthesizing intermetallic compounds. Mechanical alloying is one of the solid state methods, which is suitable for producing compounds with high steam pressure and elements with different melting points that are not produced using the conventional methods $[15,16]$. Also, this method can be used to directly produce nanocrystalline structures [17].

Formation of $\mathrm{NiAl}$ intermetallic compound during mechanical alloying is a self-expanding reaction in separate particles, which is accompanied by a sudden release of energy and thermodynamic factors play an effective role in the formation of final phase. One of the elements which promotes the deficiencies of intermetallic compounds is molybdenum and its most useful effect is in terms of increasing room temperature ductility of this compound [18]. Main effect of negligible element such as $\mathrm{Fe}, \mathrm{Ga}$, and $\mathrm{Mo}$ on microstructure of NiAl alloy is the formation of a solid solution with NiAl intermetallic compound. Adding Mo leads to a different behavior from adding $\mathrm{Fe}$ and $\mathrm{Ga}$. Also, adding Mo has slight tendency to modify grain size of $\mathrm{NiAl}$ alloy. Average grain size in the presence of Mo is less than $20 \mathrm{~nm}$, while it is $20-50 \mathrm{~nm}$ in $\mathrm{NiAl}$ alloy Mo-free [19].

Therefore, to promote mechanical properties of NiAl intermetallic compound, this paper sought to examine the effect of Mo microalloy on the production process of nanocrystalline $\mathrm{Ni}-\mathrm{Al}$ intermetallic compound. All the alloys were obtained from pure elements with a combination close 
to the stoichiometric NiAl compound using mechanical alloying.

\section{Experimental Procedure}

In this study, aluminum powders with the purity of more than $99 \%$ and particle size of less than $200 \mu \mathrm{m}$, nickel powders with the purity of more than $99.9 \%$ and particle size of less than $10 \mu \mathrm{m}$, and molybdenum powders with the purity of more than $99.99 \%$ and particle size of less than $150 \mu \mathrm{m}$ were used. The powder mixtures were milled in a planetary ball mill. The mill atmosphere was protected by argon gas to prevent the oxidation of powder particles. In all the experiments, 4 large and 12 small balls with the respective diameters of 2 and $1 \mathrm{~cm}$ were used. By selecting different sizes, the balls chose a random motion [20] and more energy was transferred to the powder [21]. Vial and balls were made of hardened chrome steel. Total weight of the used powder was $12 \mathrm{~g}$. Rotation speed of milling vial was constant in all experiments and equal to $250 \mathrm{rpm}$. Ball to powder weight ratio was $15: 1$. By changing the amount of molybdenum, 5 samples were prepared with the composition of $\mathrm{Ni}_{50} \mathrm{Al}_{50-x} \mathrm{Mo}_{x}(x=0,0.5,1,2.5,5)$ which were milled for $128 \mathrm{~h}$.

Structural changes of the samples during mechanical alloying were studied using a Philips X'Pert diffractometer with $\mathrm{Cu}-\mathrm{K} \alpha(\lambda=0.15405 \mathrm{~nm})$ radiation over 20-100 $2 \theta$. Morphology and microstructure of powder particles were characterized by SEM in a Philips XL30. The mean powder particle size was estimated from SEM images of powder particles by image tool software. The average size of about 50 particles was calculated and reported as mean powder particle size. Crystallite size and lattice strain were also calculated using Williamson-Hall method [22]. In this method, peak width caused by lattice strain and grain size is considered $[23,24]$. This relationship is expressed as follows:

$$
\beta \cos \theta=\frac{0.9 \lambda}{D}+2 \varepsilon \sin \theta
$$

where $\beta$ is the peak breadth in midheight, $\lambda$ represents the $\mathrm{X}$-ray wave length of the incident copper X-ray radiation, $D$ is the average crystallite size, $\varepsilon$ is the mean value of internal strain, $\theta$ is the Bragg diffraction angle, and $K$ is a constant with a value of 0.89 . Accordingly, if $\beta \cos \theta$ is plotted in terms of $\sin \theta$, a line with the slope of $2 \varepsilon$ and intercept of $0.9 \lambda / D$ will be obtained. By extracting these data from the drawn lines, size of crystals and lattice strain can be determined and their effect can be also separately specified. In order to determine width of peaks at half height, Sigma Plot 12.0 software, which is advanced software in drawing and processing curves, was used. Powders produced by milling were converted into tablet-like pieces with the diameter of $25 \mathrm{~mm}$ and thickness of $3 \mathrm{~mm}$ during mechanical cold pressing process under the pressure of $849 \mathrm{MPa}$ in $20 \mathrm{sec}$. Samples were studied using Vickers microhardness method with the applied force of $254.2 \mathrm{mN}$ for $10 \mathrm{sec}$ using Struers Duramin hardness tester. The reported hardness value was the average of 6 times of hardness test for each sample.

\section{Results and Discussion}

3.1. Morphology and XRD Analysis. Figures 1 and 2 show SEM images and average size of powder particles in terms of change in the amount of molybdenum after $128 \mathrm{~h}$ of milling, respectively. As shown in Figure 2, with increasing the atomic percent of molybdenum, average particle size of the powder followed a decreasing trend. Minimum average particle size of the powders containing 5 at.\% Mo was obtained as approximately $0.5 \mu \mathrm{m}$. Higher magnification of powder particles showed that large particles in this step were in fact the result of the accumulation of a large number of small particles [25]. Further, Figure 3 demonstrates X-ray diffraction pattern of the mixture of initial powder and mechanical alloying samples with different molybdenum percentages after $128 \mathrm{~h}$ of milling. As seen in the XRD patterns of the samples before milling, only the peaks of $\mathrm{Ni}, \mathrm{Al}$, and Mo were observed. With increasing Mo percentage, NiAl peaks intensity and width were reduced and increased, respectively.

After $128 \mathrm{~h}$ of milling, there was no trace of nickel and aluminum peaks in the XRD pattern (Figure 3). Reactions finished in the vial before milling completion and the final product was $100 \%$ nickel aluminide. Since the atomic diffusion is time dependent, therefore sufficient milling time is required to obtain the final products [26]. After the formation of $(\mathrm{Ni}, \mathrm{Al})$ solid solution and continuing the process of milling and topical heating, powder particles were gradually converted into NiAl. The main factors that affect the mechanisms occurring in MA process are fracture and cold welding repetition of particles followed by an increase in their [27]. For reactivity in long time periods, the powders became so homogeneous that rapidly got regulated. Powders became finer and particles size distribution went uniform with spherical and same-sized shapes. This issue showed the equality of cold welding rate and failure of powders due to cold working. With increasing the amount of molybdenum, more molybdenum was dissolved in $\mathrm{NiAl}$ intermetallic given the changes in lattice parameters. As a result of Mo dissolution in $\mathrm{NiAl}$ intermetallic compound, stacking faults energy was reduced and effect of hard working became higher than that of the molybdenum-free sample, more dislocations and subboundaries were formed, and consequently grain sizes became finer. Furthermore, by the dissolution of Mo atoms in the Ni matrix, hardworking effects were increased; as a result, more powder particles were brittle and more failure occurred in them which led to finer particles. In general, dissolution of alloying elements in metal crystals and generation of distortion in them increase hard working in the cold working process $[28,29]$. In fact, Mo saturation in Ni reduces such an effect.

3.2. Internal Strain. Figure 4 shows internal strain changes of NiAl lattice for different percentages of molybdenum after $128 \mathrm{~h}$ of milling. As is determined, with increasing the amount of molybdenum, first, a strong increase occurred in the rate of received internal strain. Then, at 2.5 at.\% Mo, the amount of internal strain stored in powder particles increased with less intensity. In addition to the internal strain transferred to the powder particles from the milling device, 

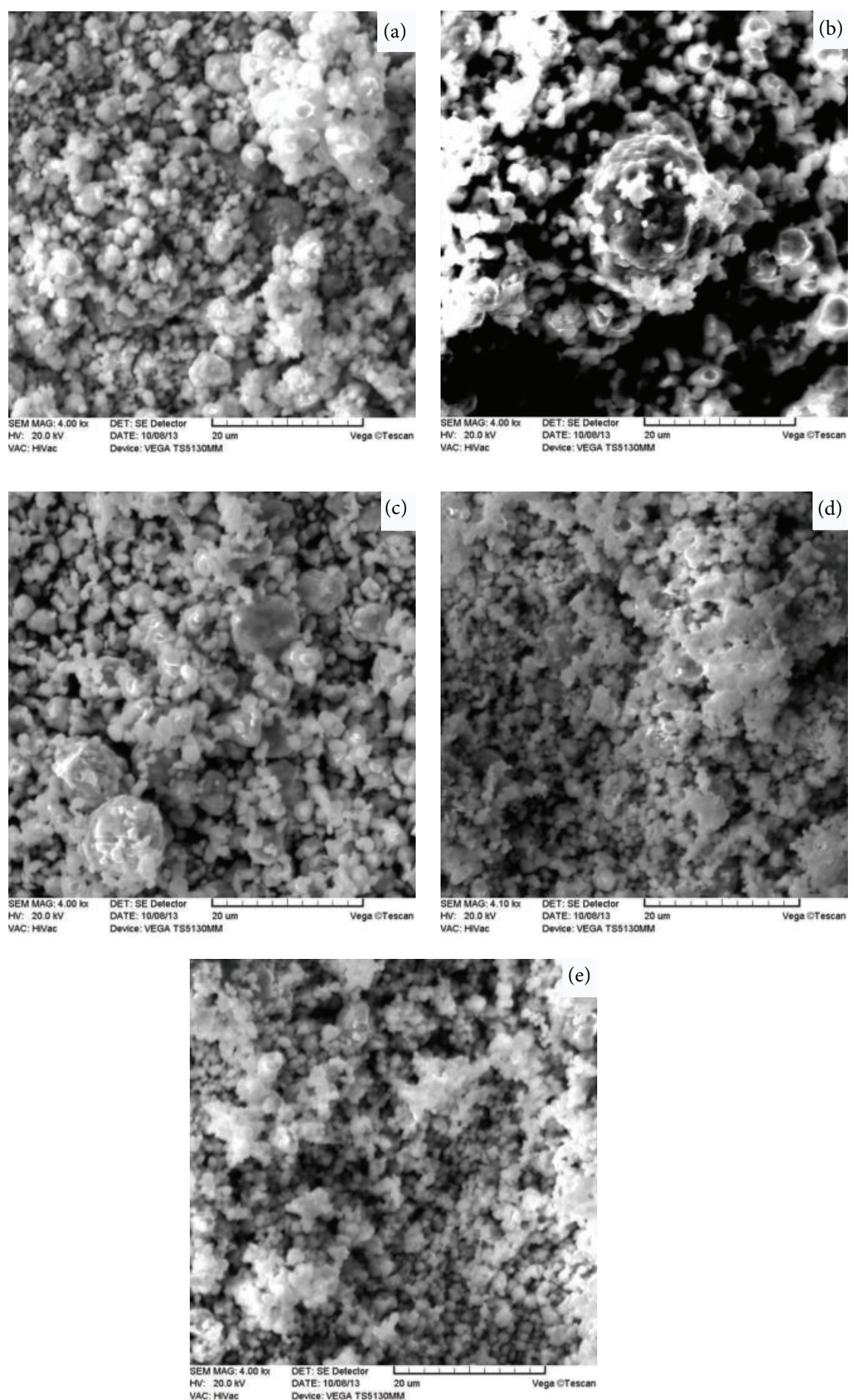

FIGURE 1: SEM images of powders milled for $128 \mathrm{~h}$ in (a) 0 , (b) 0.5 , (c) 1, (d) 2.5, and (e) 5 at.\% Mo.

with increasing molybdenum and dissolution of its atoms in Ni matrix, more defects, specifically dislocations, were formed in the materials. As a result, strain of the material increased compared to molybdenum-free NiAl compound. Nevertheless, with increasing molybdenum content to more than 2.5 at.\%, increased accumulation of cold working effect led to matrix saturation of cold working and reduced strain increase rate at high amounts of molybdenum. Alizadeh et al.
[30] reported increased internal strain in NiAl system with the increased $\mathrm{Cr}$ atomic percent and showed that high levels of chromium had a more impact than molybdenum on the internal strain of $\mathrm{NiAl}$.

3.3. Crystal Size. Figure 5 shows effect of the amount of molybdenum on changes in the size of NiAl crystals after $128 \mathrm{~h}$ of milling. Crystal size in $\mathrm{NiAl}$ molybdenum-free 


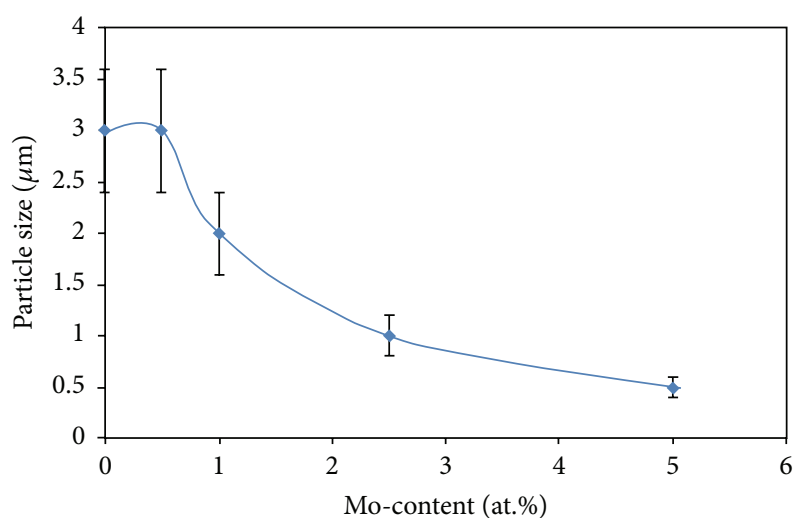

Figure 2: Average particle size of the powder for different amounts of molybdenum after $128 \mathrm{~h}$ of milling.

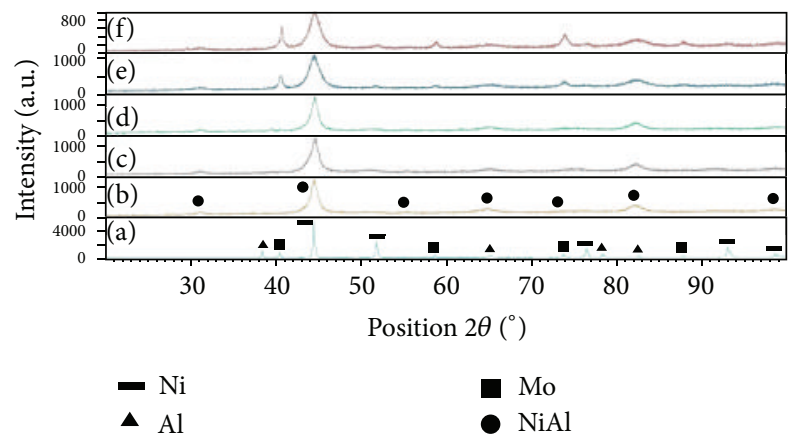

FIGURE 3: X-ray diffraction pattern of (a) nonmilled powder mixture and $128 \mathrm{~h}$ milling of (b) $\mathrm{Ni}_{50} \mathrm{Al}_{50}$, (c) $\mathrm{NiAl}_{49.5} \mathrm{Mo}_{0.5}$, (d) $\mathrm{NiAl}_{49} \mathrm{Mo}_{1}$, (e) $\mathrm{NiAl}_{47.5} \mathrm{Mo}_{2.5}$, and (f) $\mathrm{NiAl}_{45} \mathrm{Mo}_{5}$.

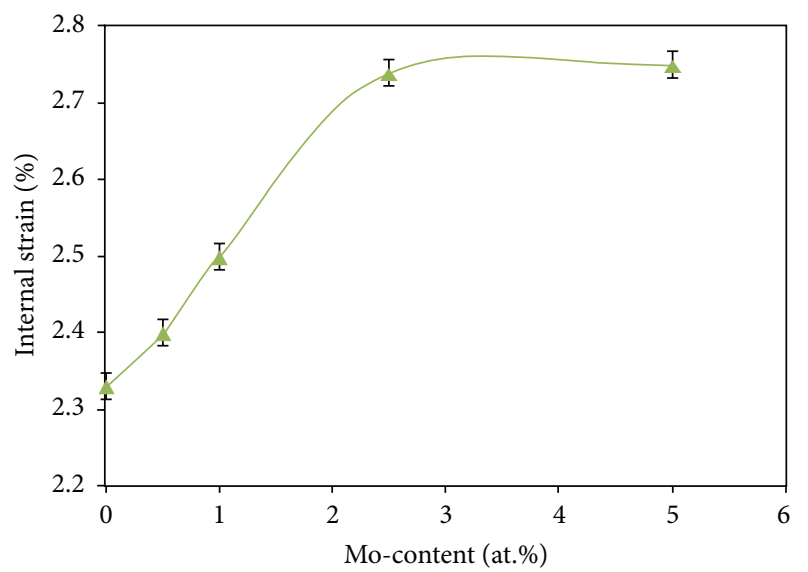

FIGURE 4: Strain changes of NiAl lattice after $128 \mathrm{~h}$ of milling for the 5 samples with $0,0.5,1,2.5$, and 5 at. $\%$ Mo.

samples after $128 \mathrm{~h}$ of milling was $26 \mathrm{~nm}$ and with increasing molybdenum up to 5 at.\%. This value was decreased to $10 \mathrm{~nm}$. With increasing molybdenum, crystallite size suddenly decreased for the powders containing 0.5 at.\% Mo, but this trend reached saturation with more increase of molybdenum, which can be due to the solubility saturation of

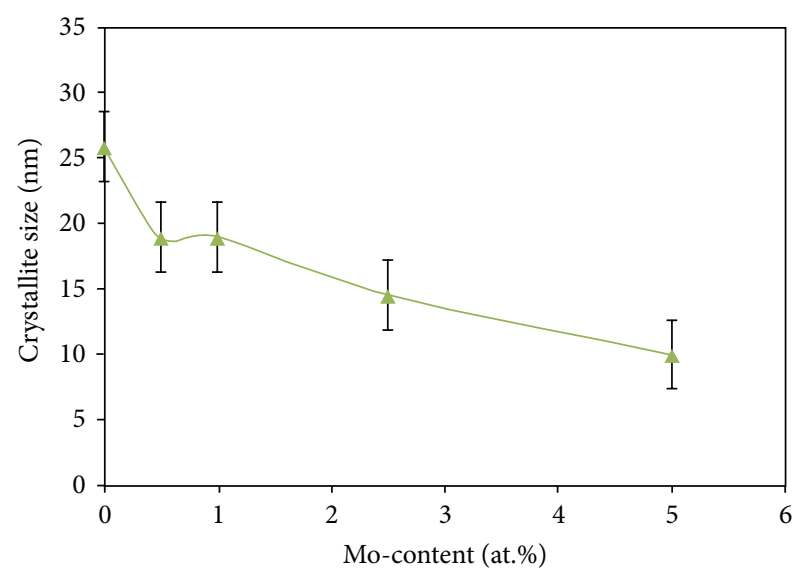

FIGURE 5: Size changes of NiAl crystal after $128 \mathrm{~h}$ of milling for samples with $0,0.5,1,2.5$, and 5 at. $\%$ Mo.

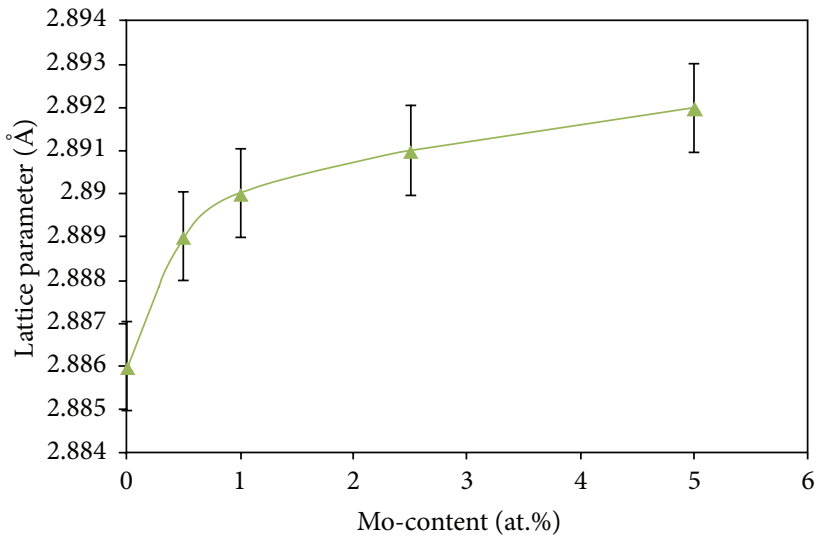

FIGURE 6: Changes of NiAl lattice parameter after $128 \mathrm{~h}$ of milling for the 5 samples with $0,0.5,1,2.5$, and 5 at. $\%$ Mo.

Mo atoms in nickel lattice. As a result, hardworking effect was reduced and consequently dislocations and subboundaries were formed to some extent and then the intensity of crystallite size reduction was decreased. Intense grain size reduction is one of the methods for improving ductility so that nanometric dimensions of grains led to further improvement in ductility and creeping resistance compared to micron grains [31, 32]. Above DBTT temperature, there was strong dependence between tensile ductility and grain size [33]. Room temperature yield strength of $\mathrm{Ni}_{50} \mathrm{AL}$ is independent of grain size; in contrast, even in alloys with small deviation from stoichiometry, it strongly depends on grain size and increased with the reduction in grain size [34].

3.4. Lattice Parameter. Figure 6 demonstrates changes in the lattice parameter of NiAl compound after $128 \mathrm{~h}$ of milling for different atomic percentages of molybdenum. According to this figure, lattice parameter had one increase for the powders containing 1 at.\% Mo, but this trend reached a stable state with more Mo increase, which could be due to solubility saturation of Mo atoms in Ni lattice; consequently, intensity of increasing lattice parameter was reduced. Albiter et al. 


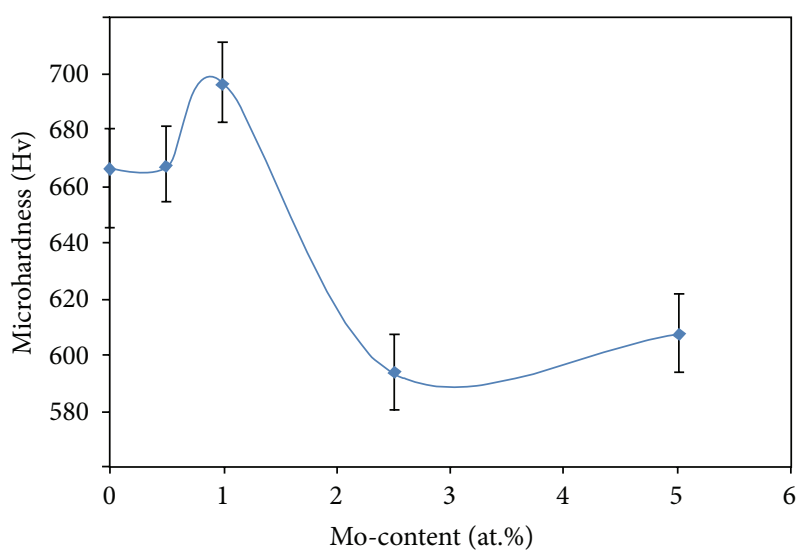

FIGURE 7: Microhardness changes after $128 \mathrm{~h}$ of milling for the 5 samples with $0,0.5,1,2.5$, and 5 at.\% Mo.

[19] added molybdenum to $\mathrm{Ni}_{56} \mathrm{Al}_{44}$ compound and reported similar results. They also reported that adding $\mathrm{Fe}$ to the same compound had a more effect on lattice parameter than Mo. The reason for more increase of lattice parameter with increasing molybdenum could be attributed to increased crystal defects and then dislocations as a result of severe plastic deformation of particles. Thus, subgrains were formed; subgrains and dislocations made vaster pathways for the movement of molybdenum atoms and were displaced by more plastic deformation of particles; however, molybdenum atoms were not displaced. By repetition, there would be an increased possibility for the penetration of Mo atoms.

3.5. Microhardness Measurements. Figure 7 shows microhardness changes in NiAl lattice after $128 \mathrm{~h}$ of milling for different percentages of molybdenum after cold pressing operations. As can be seen, with increasing molybdenum, microhardness changes first increased and then decreased. Microhardness changes in NiAl sample without molybdenum showed the number of $660 \mathrm{Hv}$ after $128 \mathrm{~h}$ of milling. With increasing the amount of Mo to $1 \%$, a sharp increase up to $690 \mathrm{Hv}$ was observed in microhardness rate. Then, at 2.5 at.\% Mo, this value was reduced to $603 \mathrm{Hv}$ and, afterward, it remained almost constant.

This complexity can be considered as the interaction of two processes: one is cold working process that occurs before and after the formation of NiAl compound and the other is the formation of $\mathrm{NiAl}$ intermetallic compound that leads to heat release. With increasing atomic percent of molybdenum, more cold working effects were stored in $(\mathrm{Ni}, \mathrm{Al})$ solid solution and thus more energy was stored there. As a result, during the random conversion of $(\mathrm{Ni}$, $\mathrm{Al})$ solid solution into a regular intermetallic compound, more heat was released. More heat release would completely eliminate the remaining cold working effects generated in the $(\mathrm{Ni}, \mathrm{Al})$ solid solution. This factor could cause more hardness drop at high molybdenum amounts. Therefore, several factors are effective in this regard and it needs to be further investigated since: this subject and cold working elements during mechanical alloying and before and after the formation of NiAl intermetallic compound are complex; after the formation of intermetallic compound, heat is released and both material and phase change and at the same time, in addition to phase change, the structure itself can change under the influence of the two above-mentioned elements.

\section{Conclusions}

Nanocrystalline $\mathrm{Ni}_{50} \mathrm{Al}_{50-x} \mathrm{Mo}_{x}(x=0,0.5,1,2.5,5)$ intermetallic compound was successfully produced by mechanical alloying of different amounts of molybdenum. Molybdenum increase led to increased defects in the material, especially dislocations. As a result, strain rate of the material increased compared to NiAl compound. Increasing Mo not only reduced the final crystallite size but also had an important effect on modifying microstructure. Variations in crystallite size were very severe at first and decreased later when reaching saturation. Crystal size in the NiAl molybdenum-free sample was $26 \mathrm{~nm}$ and increasing Mo to 5 at.\% reduced it to $10 \mathrm{~nm}$. Mo increase to $1 \%$ intensely increased microhardness rate to $690 \mathrm{Hv}$. Broadening peaks of X-ray diffraction pattern due to molybdenum increase were mainly due to decreased crystallite size and increased lattice strain. In the presence of molybdenum, the produced alloy's lattice parameter showed higher values.

\section{Conflict of Interests}

The authors declare that there is no conflict of interests regarding the publication of this paper.

\section{References}

[1] S. Eghtesadi, N. Parvin, M. Rezaee, and M. Salari, "Mechanically induced driving forces in preparing W-Cu nanocomposite," Journal of Alloys and Compounds, vol. 473, no. 1-2, pp. 557-559, 2009.

[2] N. Duman, A. O. Mekhrabov, and M. V. Akdeniz, "Microalloying effects on the microstructure and kinetics of nanoscale precipitation in Ni-Al-Fe alloy," Intermetallics, vol. 23, pp. 217227, 2012.

[3] R. D. Noebe, R. R. Bowman, and M. V. Nathal, "Physical and mechanical properties of the B2 compound NiAl," International Materials Reviews, vol. 38, no. 4, pp. 193-232, 1993.

[4] D. B. Miracle, "Overview no. 104 the physical and mechanical properties of NiAl," Acta Metallurgica Et Materialia, vol. 41, no. 3, pp. 649-684, 1993.

[5] E. George, M. Yamaguchi, K. Kumar, and C. Liu, "Ordered intermetallics," Annual Review of Materials Science, vol. 24, pp. 409-451, 1994.

[6] C.-K. Lin, S.-S. Hong, and P.-Y. Lee, "Formation of NiAl$\mathrm{Al}_{2} \mathrm{O}_{3}$ intermetallic-matrix composite powders by mechanical alloying technique," Intermetallics, vol. 8, no. 9-11, pp. 10431048, 2000.

[7] H.-P. Chiu, J.-M. Yang, and R. Amato, "A study of fiber coating in $\mathrm{Al}_{2} \mathrm{O}_{3}$ fiber-reinforced NiAlFe matrix composites," Materials Science and Engineering A, vol. 203, no. 1-2, pp. 81-92, 1995.

[8] C. Liu, S. M. Jeng, J.-M. Yang, and R. A. Amato, "Processing and high temperature deformation of $\mathrm{Al}_{2} \mathrm{O}_{3}$ fiber-reinforced NiAlFe 
matrix composites," Materials Science and Engineering A, vol. 191, no. 1-2, pp. 49-59, 1995.

[9] D. R. Johnson, X. F. Chen, B. F. Oliver, R. D. Noebe, and J. D. Whittenberger, "Processing and mechanical properties of in-situ composites from the NiAl-Cr and the NiAl-(Cr,Mo) eutectic systems," Intermetallics, vol. 3, no. 2, pp. 99-113, 1995.

[10] M. S. Choudry, M. Dollar, and J. A. Eastman, "Nanocrystalline NiAl-processing, characterization and mechanical properties," Materials Science and Engineering A, vol. 256, no. 1-2, pp. 25-33, 1998.

[11] L. Sheng, W. Zhang, J. Guo, F. Yang, Y. Liang, and H. Ye, "Effect of Au addition on the microstructure and mechanical properties of NiAl intermetallic compound," Intermetallics, vol. 18, no. 4, pp. 740-744, 2010.

[12] R. J. Thompson, J.-C. Zhao, and K. J. Hemker, "Effect of ternary elements on a martensitic transformation in $\beta$-NiAl," Intermetallics, vol. 18, no. 5, pp. 796-802, 2010.

[13] G. Smola, W. Wang, J. Jedliński et al., "Mechanistic aspects of Pt-modified $\beta$-NiAl alloy oxidation," Materials at High Temperatures, vol. 26, no. 3, pp. 273-280, 2009.

[14] A. Mashreghi and M. M. Moshksar, "Partial martensitic transformation of nanocrystalline NiAl intermetallic during mechanical alloying," Journal of Alloys and Compounds, vol. 482, no. 1-2, pp. 196-198, 2009.

[15] C. Suryanarayana, "Mechanical alloying and milling," Progress in Materials Science, vol. 46, no. 1-2, pp. 1-184, 2001.

[16] J. García Barriocanal, P. Pérez, G. Garcés, and P. Adeva, "Microstructure and mechanical properties of $\mathrm{Ni}_{3} \mathrm{Al}$ base alloy reinforced with Cr particles produced by powder metallurgy," Intermetallics, vol. 14, no. 4, pp. 456-463, 2006.

[17] M. H. Enayati, F. Karimzadeh, and S. Z. Anvari, "Synthesis of nanocrystalline NiAl by mechanical alloying," Journal of Materials Processing Technology, vol. 200, no. 1-3, pp. 312-315, 2008.

[18] R. Darolia, D. Lahrman, and R. Field, "The effect of iron, gallium and molybdenum on the room temperature tensile ductility of NiAl," Scripta Metallurgica et Materiala, vol. 26, no. 7, pp. 10071012, 1992.

[19] A. Albiter, E. Bedolla, and R. Perez, "Microstructure characterization of the NiAl intermetallic compound with Fe, Ga and Mo additions obtained by mechanical alloying," Materials Science and Engineering A, vol. 328, no. 1, pp. 80-86, 2002.

[20] L. Takacs, "Ball milling-induced combustion in powder mixtures containing," in Processing and Properties of Nanocrystalline Materials, C. Suryanarayana, Ed., pp. 453-464, TMS, Warrendale, Pa, USA, 1996.

[21] D. Gavrilov, O. Vinogradov, and W. Shaw, "Simulation of mechanical alloying in a shaker ball mill with variable size particle," in Proceedings of the 10th International Conference on Composite Materials (ICCM '10), pp. 299-307, Woodhead Publishing, 1995.

[22] G. K. Williamson and W. H. Hall, "X-ray line broadening from filed aluminium and wolfram," Acta Metallurgica, vol. 1, no. 1, pp. 22-31, 1953.

[23] C. Suryanarayana and M. G. Norton, X-Ray Diffraction: A Practical Approach, Springer, Berlin, Germany, 1998.

[24] B. Cullity, Elements of X-Ray Diffraction, Addison-Wesley, Reading, Mass, USA, 1978.

[25] M. Rafiei, M. H. Enayati, and F. Karimzadeh, "Characterization and formation mechanism of nanocrystalline $(\mathrm{Fe}, \mathrm{Ti})_{3} \mathrm{Al}$ intermetallic compound prepared by mechanical alloying," Journal of Alloys and Compounds, vol. 480, no. 2, pp. 392-396, 2009.
[26] L. Zhou, J. Guo, and G. Fan, "Synthesis of NiAl-TiC nanocomposite by mechanical alloying elemental powders," Materials Science and Engineering A, vol. 249, no. 1-2, pp. 103-108, 1998.

[27] C. Suryanarayana, Mechanical Alloying and Milling, CRC Press, 2004.

[28] G. H. Akbari and M. T. Dehaqani, "Nanostructure Cu-Cr alloy with high dissolved $\mathrm{Cr}$ contents obtained by mechanical alloying process," Powder Metallurgy, vol. 54, no. 1, pp. 19-23, 2011.

[29] M. Azimi and G. Akbari, "Development of nano-structure Cu$\mathrm{Zr}$ alloys by the mechanical alloying process," Journal of Alloys and Compounds, vol. 509, no. 1, pp. 27-32, 2011.

[30] M. Alizadeh, G. Mohammadi, G.-H. A. Fakhrabadi, and M. M. Aliabadi, "Investigation of chromium effect on synthesis behavior of nickel aluminide during mechanical alloying process," Journal of Alloys and Compounds, vol. 505, no. 1, pp. 64-69, 2010.

[31] S. Raj, "Creep behavior of near-stoichiometric polycrystalline binary alloy," NASA TM-2002-2 112 10, Glenn Research Center, Cleveland, Ohio, USA, 2002.

[32] E. Bonetti, E. G. Campari, L. Pasquini, E. Sampaolesi, and G. Scipione, "Mechanical behaviour of $\mathrm{NiAl}$ and $\mathrm{Ni}_{3} \mathrm{Al}$ ordered compounds entering the nano-grain size regime," Nanostructured Materials, vol. 12, no. 5-8, pp. 895-898, 1999.

[33] K. S. Chan, "Theoretical analysis of grain size effects on tensile ductility," Scripta metallurgica et materialia, vol. 24, no. 9, pp. 1725-1730, 1990.

[34] R. D. Noebe, R. R. Bowman, and M. V. Nathal, The Physical and Mechanical Metallurgy of NiAl, Springer, 1996. 

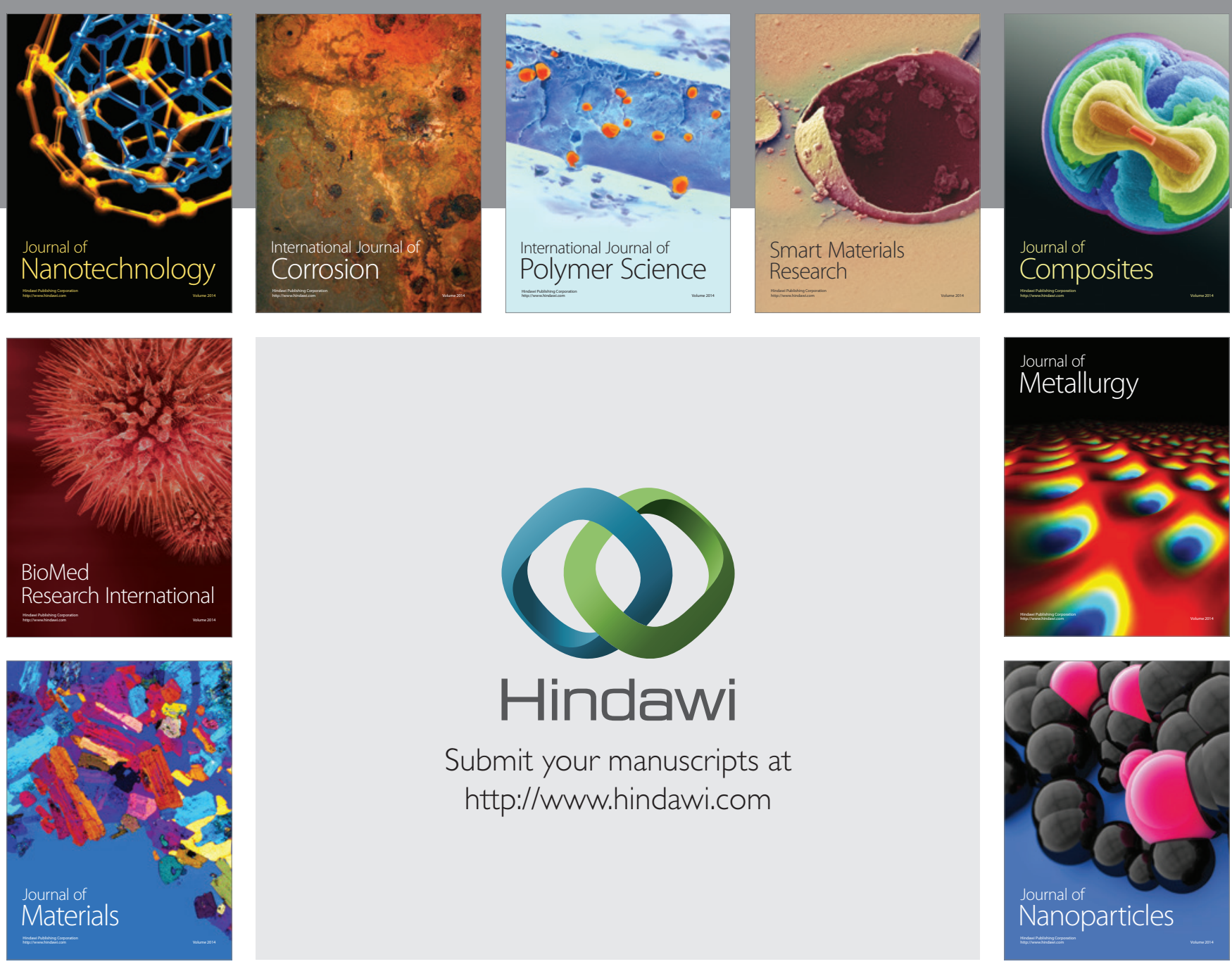

Submit your manuscripts at http://www.hindawi.com
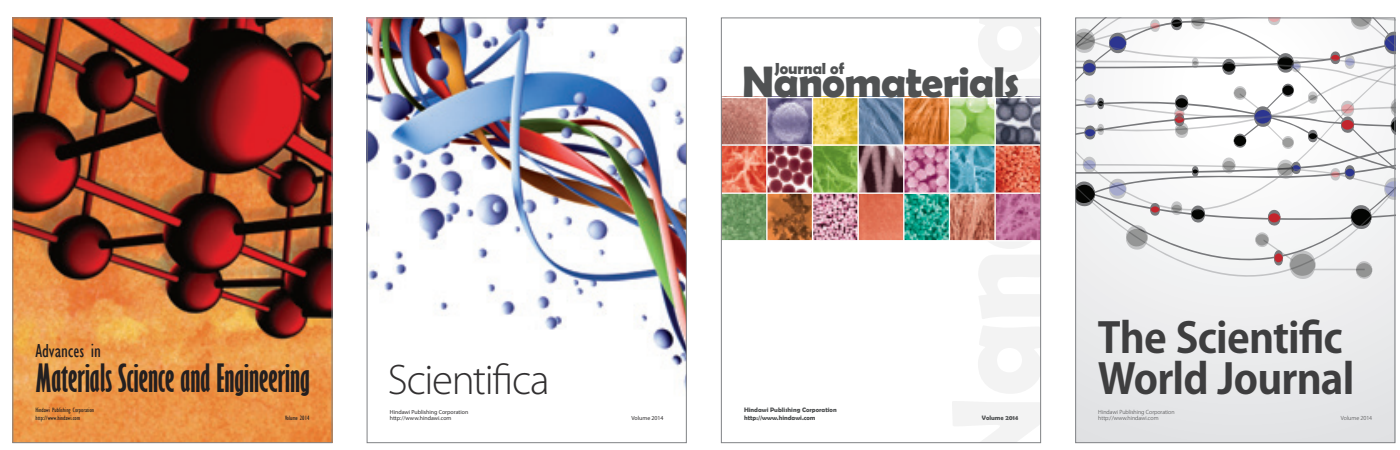

\section{The Scientific World Journal}
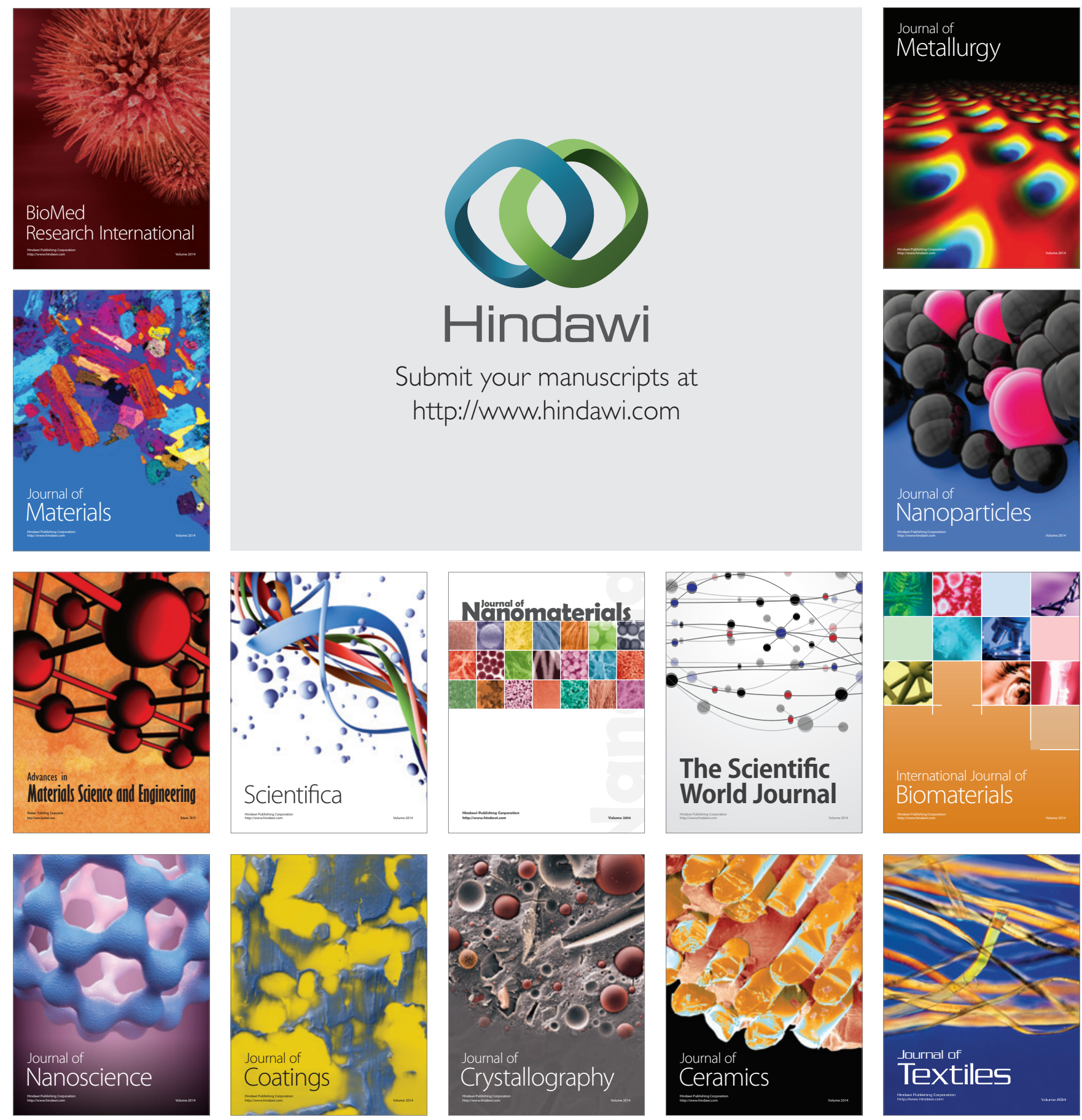